Article

\title{
Mission Accomplished? Critique, Justification, and Efforts to Diversify Gifted Education
}

\author{
Arne Böker \\ Institute for Higher Education Research (HoF), Martin Luther University of Halle-Wittenberg, Germany; \\ E-Mail: arne.boeker@hof.uni-halle.de
}

Submitted: 30 March 2021 | Accepted: 19 May 2021 | Published: 16 September 2021

\begin{abstract}
Research on gifted education demonstrates how these programs contribute globally to the reproduction of social inequalities. Despite these findings, gifted education has been remarkably successful in the 21st century. However, the need to equate the inclusion of women, first-generation students, and students with a migration background in gifted education has simultaneously intensified. Both developments are embedded in profound transformations of the education system globally, especially in the social diversification of student populations and the concurrent demand for excellence in academic research. The German Academic Scholarship Foundation (Studienstiftung) is the largest gifted education program in Germany and one of the oldest worldwide. In recent years, the Studienstiftung has tried to diversify their students. Based on a discourse analysis, which uses the concepts of justification, critique, and regimes of justification, I examine official documents of the Studienstiftung between 1925 and 2018. In doing so, I show that the spirit of the Studienstiftung and their handling of social statistics raise doubts concerning the successful diversification of their students-as the Studienstiftung has claimed. Finally, I discuss several measures that might be useful to support social diversification in gifted education in the future.
\end{abstract}

\section{Keywords}

diversification in higher education; exclusion; gifted education; German Academic Scholarship Foundation; social inequalities; sociology of justification

\section{Issue}

This article is part of the issue "Education, Politics, Inequalities: Current Dynamics and Perspectives" edited by Kenneth Horvath (University of Lucerne, Switzerland) and Regula Julia Leemann (University of Teacher Education FHNW, Switzerland / University of Basel, Switzerland).

(C) 2021 by the author; licensee Cogitatio (Lisbon, Portugal). This article is licensed under a Creative Commons Attribution 4.0 International License (CC BY).

\section{Introduction}

Since their establishment in Europe and the United States at the beginning of the 20th century, gifted education programs have been remarkably successful over time. However, the ensuing expansion of gifted education has been consistently criticised by social scientists, who have demonstrated that gifted education is often linked to the reproduction of social inequalities, especially regarding class, race, and gender (see Böker \& Horvath, 2018; Margolin, 1994; Staiger, 2004). In this article, I present a case study on the German Academic Scholarship Foundation (Studienstiftung), which was founded in 1925, liquidated by the Nazis in 1934, and re-established in 1948 in the Federal Republic of Germany (see Kunze, 2001). The Studienstiftung is one of the oldest gifted education programs worldwide and by far the largest in Germany's higher education system.

The recent history of the Studienstiftung is characterised by a massive expansion (2005-2009), followed by harsh public criticism of its exclusion of first-generation students (FGS) and students of low social status, and intensive efforts to justify its selection procedure since 2009. The year 2009 can be considered a major turning point in the history of the Studienstiftung, where a general shift from excellence to diversity is observable (Böker, 2021). In general, the Studienstiftung had to react to the critique that it supported a "self-reproduction of 
the German Bildungsbürgertum [educated elite]" and that their selection interviews "do not focus on specialised knowledge, but on knowledge about art and literature" (Kerbusk, 2009). Due to these critiques, the Studienstiftung introduced different measures like a new selection procedure, cooperation with organisations that focus on social equity, an additional recommendation of FGS by school principals, the sensibilisation of the selection committee to the issue of social inequality, school visits by Studienstiftung scholars to inform students about the opportunity to apply for a scholarship, and two social surveys. After the Studienstiftung published a social survey in 2016, it concluded that their selection procedure was fair and did not discriminate against students from lower social classes and FGS.

In this article, I shed light on the interplay of critique, justification, and organisational change concerning the plea for social diversity in higher education. I will show in depth how the Studienstiftung reacts to critique and how it adopts their selection and support procedures. I am interested in how these critiques and justifications are structured and how they have developed over time. I use a genealogical approach to relate recent efforts to include FGS in the history of the Studienstiftung since 1925. Two aspects challenge the recent conclusion that the Studienstiftung does not discriminate students from lower social class and FGS. First, the specific culture of Studienstiftung, which is rooted in their foundation in 1925 and tends to culturally exclude students from lower social class and FGS. Second, the strategies to construct and interpret social statistics, which originated in the 1970 s, tend to make social inequalities in gifted education invisible and make it difficult to problematise and tackle them.

In the next section of this article, I discuss several studies that aim to describe why and how gifted education fails to support the social diversification of gifted students. Then, after a brief overview of the theoretical and methodological foundation of this research, I present two findings regarding the spirit of the Studienstiftung and its handling of social statistics, which deepen our understanding of the interplay of critique, justification, and organisational change. Finally, I discuss measures that could support the diversification of gifted students.

\section{Why and How Gifted Education Fails to Diversify Its Student Population}

The most common approach to describing the mechanisms that prevent diversification in gifted education can be found in the work of Bourdieu. He believes that the disproportional participation of working-class students in gifted education programs can be explained by the transmission of cultural capital within the family, the self-exclusion of potential candidates and the specific culture of gifted education programs (see Bourdieu, 2001). Above all, Bourdieu points out that these mechanisms are generally obscured by references to natural differences in the amount of giftedness. This ideology, which he calls the ideology of giftedness, is shared not only by the oppressed but also by the dominators (see Bourdieu, 1993, pp. 252-253). After studying almost one hundred years of justification of gifted education by the Studienstiftung, I can state that a reference to natural differences in the amount of giftedness, to explain unequal opportunities for participation, is seldom used in the official representation. Subsequently, when such a strategy is used, it is criticised in the mass media discourse (see Böker, 2021). This does not mean, however, that the ideology of giftedness does not exist; rather, it shows that the official representation of gifted education is organised differently.

Since the 1990s, social scientists have been intensively studying the social construction of giftedness and the interdependence of gifted education programs with the (re-)production of social inequalities. Following Bourdieu, Margolin (1994) describes how the writings of gifted education scholars at the beginning of the 20th century are linked to a specific culture. He shows that the understanding of gifted children as an exclusive, social, and needy group can be interpreted as a process of people-making, in which mainly researchers have been involved. However, the descriptions of gifted children are linked mainly to the vocabulary, values, and institutions of the white upper-middle class. Beyond that, the obvious underrepresentation of working-class and black students was for these researchers a proof of the supremacy of the white upper-middle class, which is why the lack of diversification among gifted students was not challenged. In this sense, the emergence of gifted children can be interpreted as a strategy of the dominant class to preserve a specific "social order, a class, a race, a community, a culture" (Margolin, 1994, p. 3). The emergence of gifted children as a social group is a good example of how the ideology of giftedness materialises and how it prevents the social diversification of gifted students.

Staiger (2004) sheds light on the processes of how official representation is arranged in gifted education programs. The starting point of her study is the observation of a highly disproportional lack of participation among black students in an exclusive gifted education program within the investigated urban high school. In contrast, black students are overrepresented among the school's student population in general. Staiger realises that giftedness is used as a code word for whiteness and argues that the program for gifted students can be read as a racial project. The handling of social statistics is a core element in obscuring this mechanism and establishing successful narratives about the school. The first narrative includes social statistics published on the official website of the school that show that students inside the regular school and the gifted program both perform at an excellent academic level. However, Staiger demonstrates that these statistics are arranged in such a way as to exaggerate the performance of 
students in the regular school. While the performance of the regular school is comparable to other schools in the district, the students within the gifted program perform at an outstanding level. The second narrative is based on a success story that claims the inclusiveness of the school in general. Indeed, social statistics of the school are used to hide the racial breakdown within the gifted program. Furthermore, the school management refused to show social statistics to Staiger and even denied their existence. She needed several years to obtain the data, which was only possible by circumventing official institutions.

\section{Justification of Gifted Education on the Level of Discourse}

This article is grounded in the sociology of knowledge approach to discourse (SKAD). This approach can be described as a "research agenda and a theorymethodology-methods package aiming to examine the discursive construction of realities in social relations of knowledge and knowing and in the social politics of knowledge and knowing" (Keller, 2018, p. 27). Offering a broad toolkit, SKAD helps to scrutinise power/knowledge regimes, especially concerning the interdependence between actors and discourse. I analyse written texts of the Studienstiftung, primarily annual reports and journal articles published between 1925 and 2018. Based on these official documents, I reconstruct the specific discourse of the Studienstiftung. As I am interested in how this discourse evolves, my research perspective can be described as genealogical. Concerning Friedrich Nietzsche, Foucault (1974, pp. 88-96) argues that history should not be told linearly, nor from the point of the present or by subduing it under just one principle. Instead, from a genealogical perspective, the history of humankind should be understood as a series of interpretations. SKAD enables us to understand these interpretations at the level of discourse. Established concepts to reconstruct patterns of interpretations in SKAD are interpretative schemes, argumentation clusters, classifications, phenomenal structures, and narrative structures (see Keller, 2018, pp. 32-35). However, as SKAD motivates researchers to adopt and develop their toolkit in concrete research projects, I integrate the concept of regimes of justification into SKAD.

Boltanski and Thévenot (2006) argue that actors frequently refer to regimes of justification to justify something or someone in situations of crisis, uncertainty, or critique. According to SKAD, regimes of justification can be understood as different statements that share the same principle of justification. For example, Boltanski and Thévenot (2006) reconstruct a domestic regime based on a traditional principle, an inspired regime grounded on creative and individualistic principles, a market regime built on a competitive principle, and three other regimes of justification based on different principles. In everyday life, social actors are con- fronted with different situations. That is why they must constantly refer to different regimes of justification and need to adapt them. In The New Spirit of Capitalism, Boltanski and Chiapello (2007) examine the interplay of critique, justification, and societal change. They analyse the spirit of capitalism, understood in a normative sense as the "ideology that justifies engagement in capitalism" (Boltanski \& Chiapello, 2007, p. 8), and its transformation by reconstructing the plural arrangements of different regimes of justification. The authors argue that critique plays a major role in the transformation of the spirit of capitalism. Following Boltanski and Chiapello (2007), I have reconstructed the (changing) spirit of the Studienstiftung between 1925 and 2018 (see Böker, 2021). Thus, in the first part of my analysis, I focus on two regimes of justification, which are structured by the same principles. In doing so, I show how these regimes of justification might affect the diversification of gifted students (see Leemann \& Imdorf, 2018, p. 14).

Furthermore, Boltanski and Chiapello (2007) differentiate between two different forms of critique of capitalism: artistic and social critique. While artistic critique sees capitalism as a source of disenchantment, missing authenticity and oppression, social critique refers to capitalism as a source of poverty, inequality, opportunism, and egoism (Boltanski \& Chiapello, 2007, p. 79). In the history of the Studienstiftung, the most common critique focuses on the social selectivity of gifted education, which is demonstrated by social statistics (Böker, 2021). As Desrosières (2014, p. 348) argues, "social critique often relies on statistical arguments. These attempt to express and make visible exigencies of equality and justice." However, the opportunity to construct social statistics is unequally distributed and related to power. Thus, following the works of Desrosières (2014) and Espeland (2015), I concentrate in the second part of my analysis on how the critique and justification of the Studienstiftung rely on social statistics, how these statistics are constructed and interpreted, how they are intertwined with organisational change and the question of diversification of gifted education.

\section{Analysis}

In 2009, the Studienstiftung was confronted with a harsh critique in respect to the low percentage of gifted students with lower social status and FGS in their gifted program. Seven years later, and after the introduction of several measures, the Studienstiftung points out that their selection procedure is fair and does not discriminate against any student group. To better understand the approach of diversification and the ostensible occurrence of equity in gifted education I use a genealogical approach. First, I look back to the founding of the Studienstiftung in 1925 and reconstruct an important regime of justification, which I call the "defence of the tradition of academic freedom." This regime is structured by inspired and domestic principles and linked to the 
ideas of German Bildungsbürgertum. I show that these principles are still present today and are an ineluctable part of the spirit of the Studienstiftung, which makes the diversification of gifted students unlikely. Second, I go back to the early 1970s to show how the Studienstiftung have handled the public critique on failing equity for the first time in its history. Thus, I research the interplay of critique, justification, and organisational change. I can show that in the early 1970 s, and since 2009 , social statistics have played a major role in the justification process. However, the handling and interpretation of social statistics of the Studienstiftung raise doubts as to whether the diversification of gifted students has taken place. Both chapters start with a brief contextualisation of the researched period and the problems which the Studienstiftung has identified and tries to solve.

\subsection{The Spirit of the Studienstiftung}

The establishment of the Studienstiftung is linked to the fundamental crisis of the Bildungsbürgertum after the end of World War I. Members of this social class were confronted with shrinking incomes, declining assets, a disproportionally high number of deaths during World War I concerning the share of the population, and a loss of political influence (see Wehler, 2008, pp. 294-295). In addition, they were not able to compete financially with the rising mercantile upper-middle class (see Wehler, 2008, p. 285) and struggled against the educational aspirations of the middle class (see Wehler, 2008 , p. 462). Furthermore, the reproduction of the Bildungsbürgertum through the acquisition of educational degrees was challenged by educational expansion. Eventually, members of the Bildungsbürgertum were not able to study in their preferred way as educated generalists. Due to this financial, political, and cultural crisis, the establishment of the Studienstiftung can be understood as an invention of the Bildungsbürgertum, since the Studienstiftung was mainly dominated by professors and their way of thinking.

This argument can be demonstrated by looking at how members of the Studienstiftung problematised the situation of the higher education system at that time. This can be summarised as a melancholic description of the decline of the German university. First, the Studienstiftung identified the expansion of higher education as a major problem and described it as a "massification [Überfüllung] of higher education" (Sikorski, 1930 , p. 185) with several consequences, such as a "superior number of average students" (Paeckelmann, 1927, p. 75) and the "transformation of the university into an educational institution for average and below-average performing students" (Litt, 1930, p. 183). Second, the Studienstiftung described the decline of a specific German academic tradition (the tradition of academic freedom). The increase of instrumental rationality in the students thinking was seen as one reason for this development (see Paeckelmann, 1927, pp. 79-80).
This thinking is manifest in the orientation of students towards examinations, the attempt to quickly attain a university degree, and the aspiration to learn specific methods to reach a predefined goal. It was supported by the implementation of an obligatory curriculum and partial tests, the financial crisis, and the danger of unemployment. For the Studienstiftung, another reason for the decline of the tradition of academic freedom was the exclusion of members of the Bildungsbürgertum from universities. The Studienstiftung argued that this exclusion was based on its financial crisis and the increasing selection of students based on plutocratic criteria. Thus, while students from the Bildungsbürgertum might have incorporated the desired tradition of academic freedom, their inability to study accelerated the threat to this tradition.

Against this background, Studienstiftung justified its existence by presenting itself as a solution to tackle the alleged decline of the German university by defending the tradition of academic freedom. Following Boltanski and Thévenot (2006), the way Studienstiftung justifies this duty refers to two regimes of justification: The inspired and domestic regimes. This notable mixture becomes obvious in the descriptions of the tradition of academic freedom. It was characterised on the one hand by personality, freedom, openness, and subjectivity, and on the other hand by tradition, hierarchy, and ancestry. Furthermore, the tradition of academic freedom is based on the Humboldtian model of higher education, the Platonic academy, and German idealism. To do research in this tradition requires freedom, openness, and independence on the part of the researcher. The academic tradition needed to be defended in the selection and support of gifted students. Both procedures focused on experienced experts, who were responsible for recommending and selecting gifted students based on the entire personality of the candidates, which required face-to-face interviews and individual reports, and could not be captured by psychological testing methods (see Wirtschaftshilfe, 1926, pp. 30-31). Following the idea of the tradition of academic freedom, the Studienstiftung refused to define the group of gifted students. Spranger (1930, p. 165) emphasises this characteristic of the Studienstiftung and praises the indeterminacy and openness regarding the types of gifted students in the selection procedure. Concerning the support of gifted students, the Studienstiftung expected that the experts would assume responsibility for the education of the chosen scholars, following the tradition of academic freedom and preventing instrumental rationality. From the perspective of the Studienstiftung, this type of education was directly linked to students from the Bildungsbürgertum. Working-class students were especially unfamiliar with this tradition and needed to be educated in it.

The manner of problematisation and the mixture of the inspired and domestic principles in the justification process have remained intact until today. 
However, many continuities and discontinuities can be observed. Many problems the Studienstiftung identified between 1925 and 1933 continue to be articulated. Even today, the Studienstiftung problematises the expansion of higher education, the "massification" of universities, the focus on average-performing students, and the regulations within higher education. Above all, instrumental rationality in students' thinking, for instance the understanding of academic education (Bildung) as vocational training (Ausbildung), is recognised as problem. When the Studienstiftung was re-established in 1948, the decline of the German tradition of academic freedom and the exclusion of members of the Bildungsbürgertum were not rearticulated. However, since 1948, the Studienstiftung has presented itself as a solution to preserve and support the value of academic freedom. It is the goal of the Studienstiftung to enable a few students to experience this, even in times of "massification," regulation, and the dominance of average performances. In contrast to the first episode of the Studienstiftung between 1925 and 1933, all students are able and have the same opportunity to internalise the value of academic freedom. One place where this experience is possible is the summer academies, organised by the Studienstiftung since the 1970s. During summer academies, small groups of Studienstiftung scholars work together with chosen professors on specific topics in a remote place. These events are celebrated by the Studienstiftung as opportunities to study in the "original sense of academia" (Studienstiftung, 1973, p. 15) and to do research without the constraints of everyday life, as Hans Castorp did in The Magic Mountain (see Zimmermann, 1996, p. 11).

To sum up, the spirit of the Studienstiftung has always been characterised by a mixture of inspired and domestic principles. The principles can be found in two regimes of justification: the "defence of the tradition of academic freedom" (1925-1933) and the "preservation and support of academic freedom" (since 1948), which are closely connected to the ideas of German Bildungsbürgertum. The establishment of the Studienstiftung in 1925 is linked to the fundamental crisis of the Bildungsbürgertum, the problematisation of the decline of the German university, and the regime of justification "defence of the tradition of academic freedom." Some aspects of the tradition of academic freedom-such as the preference for education over vocational training, the rejection of instrumental rationality in the students' thinking, the emphasis of personalities, and the support of academic freedom-continue to be articulated by the Studienstiftung. As social scientists have shown, these aspects are linked to the culture of the upper-middle class (see, e.g., Bourdieu, 2001, pp. 29-31; Brake \& Büchner, 2012, pp. 13-15; Vester, 2015, pp. 154-155), while others (such as the concept of personality) are based on the illusio of the scientific field and do not consider external effects like social origin and gender (see Engler, 2001, pp. 449-462).
Following Bourdieu (2001) and Margolin (1994), I argue that gifted education is based on a specific culture, which can strengthen the effect of self-exclusion of potential candidates, especially students with lower social status and FGS. Spiegler (2015) has shown that this is even true for some (not all) gifted FGS, who have been proposed by their school or university to apply for a Studienstiftung scholarship and who have been supported by the Studienstiftung. Thus, these students struggle primarily with the specific culture of the Studienstiftung and are not able to identify with the self-image of this organisation.

\subsection{The Handling of Social Statistics}

The handling of social statistics by the Studienstiftung is elementary to understand how the interplay of critique, justification, and organisational change may affect the diversification of gifted students. For the first time in its history, the Studienstiftung had to justify its work concerning the disproportionally low percentage of FGS and students from the lower class between 1971 and 1974. Two events are important for this imperative to justify. First, the publication by von Ferber et al. (1970) needs to be recognised. Already in the 1960s, equality of opportunity in the educational system became a public issue. This development continued in the 1970 s and began to include gifted education. Von Ferber et al. (1970) researched the background of gifted students regarding gender, religion, and social background. They found that the underrepresentation of women, Catholics, FGS, and students from the lower class in the student population was even more pronounced in the population of gifted students (see von Ferber et al., 1970, p. 42). Second, the function of the Studienstiftung changed fundamentally under its new director Hartmut Rahn in 1970. The Studienstiftung realigned itself toward the research of exceptional giftedness in the United States. This research line was dominated by quantitative research and standardised testing, as impressively demonstrated by the founding of the Institute for Test Development and Talent Research of the Studienstiftung (ITB) in 1970, which was substantially involved in the establishment of a new selection procedure: the so-called OberprimanerAuswahl, which existed until 1983. In this selection procedure, schools are asked to choose $10 \%$ of their best students (based on their grades). These students were invited to participate in a standardised testing procedure developed and updated by the ITB. One-third of the best-performing students of this test was finally invited to a selection seminar. This development is quite impressive in light of the general criticism of standardised testing by the Studienstiftung between 1925-1933 and 1948-1969.

The realignment of the Studienstiftung was based on a description of a fundamental change in higher education in Germany, e.g., the increase in student population, the establishment of new higher education institutions, 
and the understanding of studying and doing research (see Studienstiftung, 1973). The Studienstiftung problematised its lack of adaptation to this development, especially in its adherence to the traditional selection procedure, which was rooted in the recommendation of gifted students by schools and universities, and which few schools participated in. The justification for changes inside the Studienstiftung was accompanied by annual reports and detailed evaluation studies. Between 1971 and 1974, three evaluation studies were published to answer the question of whether the Studienstiftung reproduced social inequalities, especially regarding social class background, but without any reference to the study of von Ferber et al. (1970). In these four years, different strategies were used to show that the Studienstiftung offered equal chances for workingclass students and FGS.

First, the Studienstiftung found that women, Catholics, FGS and students from rural areas were underrepresented in its program in comparison to its percentage in the student population (see Studienstiftung, 1971, pp. 61-73). However, the Studienstiftung externalised the reasons for this situation to other parts of the educational system. These social statistics were considered to be the result of an accumulation of social inequalities that had already affected the educational trajectories of young people. Thus, the problem could not be blamed on the selection process of the Studienstiftung, but on the "starting position, which is determined by the structure of the higher education system in Germany" (Studienstiftung, 1971, pp. 61-62). Ultimately, the Studienstiftung depended on recommendations from schools and universities in selecting its scholars. Nonetheless, the Studienstiftung recognised the need to establish new selection procedures because many schools did not use its right to make recommendations. As a result, it proposed the introduction of the Oberprimaner-Auswahl.

Second, the Studienstiftung arranged the social statistics in a way that showed an overrepresentation of working-class students in its program. In Table 1, the occupational group of the fathers of gifted students is differentiated along different age groups and an overall group. The basis for the calculation of the relative share is unclear because the absolute share is missing. Nonetheless, in their interpretation, the Studienstiftung focused on the relative share of working-class students of the overall group and ignored the falling relative share between the group of 55- to 59-year-old students $(28.6 \%)$ and the group of 25 - to 29 -year-old students (5.3\%) selected. One year later, the Studienstiftung compared the relative share of working-class students in the total student population in 1967-1968 (6.7\%), the former selected students between 1948 and 1968 (11.5\%), all selected students in 1971 (17.4\%), and all selected students in 1971 entering the Studienstiftung via the Oberprimaner-Auswahl (27.9\%; see Rahn \& Müller-Hansen, 1972, pp. 40-41). Rahn and MüllerHansen (1972) emphasise the substantial underrepresentation of working-class students in the total student population, which supports the strategy of externalising the problem of social inequalities to other parts of the educational system. Furthermore, the relative share of working-class students of the total population is compared to the relative share of selected students between 1948 and 1968. However, instead of using the group of 25 - to 29 -year-old students $(5.3 \%)$, the Studienstiftung refers to the overall group (11.5\%), which enables them to tell a success story: the overrepresentation of workingclass students in its program.

Third, in 1974, the Studienstiftung told another success story, which focused on the percentage of FGS in the Studienstiftung. In the annual report of the Studienstiftung, Rahn (1974) argued that $50 \%$ of all selected students in 1972 entering Studienstiftung via Oberprimaner-Auswahl did not have an academic family background. He considered this result as proof of the social fairness of the selection process of the Studienstiftung in general. At the same time, he stated that in total 206 students entered Studienstiftung via

Table 1. Occupation groups of the fathers of former Studienstiftung scholars between 1948 and 1968.

\begin{tabular}{|c|c|c|c|c|c|c|c|c|}
\hline & \multicolumn{8}{|c|}{ Age when the survey took place in 1968} \\
\hline & $\begin{array}{l}55-59 \\
\text { years }\end{array}$ & $\begin{array}{l}50-54 \\
\text { years }\end{array}$ & $\begin{array}{l}45-49 \\
\text { years }\end{array}$ & $\begin{array}{l}40-44 \\
\text { years }\end{array}$ & $\begin{array}{l}35-39 \\
\text { years }\end{array}$ & $\begin{array}{c}\text { 30-34 } \\
\text { years }\end{array}$ & $\begin{array}{c}25-29 \\
\text { years }\end{array}$ & $\begin{array}{l}\text { Overall } \\
\text { group }\end{array}$ \\
\hline No information & - & $1.5 \%$ & $3.1 \%$ & $2.5 \%$ & $2.6 \%$ & $3.8 \%$ & $2.9 \%$ & $3.0 \%$ \\
\hline Scientist, researcher & - & $2.9 \%$ & $2.2 \%$ & $2.5 \%$ & $3.8 \%$ & $3.8 \%$ & $6.4 \%$ & $3.9 \%$ \\
\hline Schoolteacher & $7.1 \%$ & $10.3 \%$ & $12.4 \%$ & $9.9 \%$ & $11.7 \%$ & $12.4 \%$ & $14.1 \%$ & $12.0 \%$ \\
\hline Public service, civil servant, employee & $21.4 \%$ & $22.1 \%$ & $15.5 \%$ & $19.3 \%$ & $19.6 \%$ & $20.4 \%$ & $22.3 \%$ & $20.1 \%$ \\
\hline Economist & $21.4 \%$ & $22.1 \%$ & $33.1 \%$ & $26.7 \%$ & $27.8 \%$ & $30.1 \%$ & $28.5 \%$ & $28.7 \%$ \\
\hline Worker, salaried craftsman & $28.6 \%$ & $8.8 \%$ & $10.8 \%$ & $13.8 \%$ & $14.8 \%$ & $10.6 \%$ & $5.3 \%$ & $11.5 \%$ \\
\hline Professional & - & $7.4 \%$ & $7.4 \%$ & $10.1 \%$ & $8.5 \%$ & $10.3 \%$ & $12.4 \%$ & $9.9 \%$ \\
\hline Artist & - & - & $1.6 \%$ & $2.2 \%$ & $1.9 \%$ & $2.1 \%$ & $1.7 \%$ & $1.9 \%$ \\
\hline \multirow[t]{2}{*}{ Other } & $21.4 \%$ & $25.0 \%$ & $13.9 \%$ & $13.0 \%$ & $9.4 \%$ & $6.5 \%$ & $6.3 \%$ & $9.0 \%$ \\
\hline & $100 \%$ & $100 \%$ & $100 \%$ & $100 \%$ & $100 \%$ & $100 \%$ & $100 \%$ & $100 \%$ \\
\hline
\end{tabular}

Source: Studienstiftung (1971, p. 68). 
Oberprimaner-Auswahl. However, he did not mention that the Studienstiftung had selected 838 students in total in 1972 and that the traditional selection process, based on the recommendations of schools and universities, was still the dominant way to enter the program (in total 431 students; see Studienstiftung, 1973, p. 26). This was the last social statistic regarding the social background of gifted students that the Studienstiftung would publish for 36 years.

In 2009, Middendorff et al. (2009) published a study with a focus on the social background of gifted students showing that students with low status were underrepresented in gifted programs in general. In the weekly newspaper Die Zeit, Kerbusk (2009) published a detailed evaluation of Middendorff et al. (2009). In particular, the social status of gifted students supported by the Studienstiftung was critically discussed. Kerbusk showed that gifted students with low status (5\%), average status (14\%), and above-average status (18\%) were underrepresented in the Studienstiftung in comparison to the average of all gifted education programs (low status: 9\%; average status: $19 \%$; above-average status: $21 \%$ ) and the total student population (low status: 14\%; average status: $25 \%$; above-average status: $24 \%$ ). In contrast, students with a high status were overrepresented in the Studienstiftung (64\%) in contrast to the average of all gifted programs (51\%) and the total student population (37\%). These results were the starting point of a debate about the reproduction of social inequality in gifted education programs, especially within the Studienstiftung. Just like in the 1970s, an external study by social scientists was the trigger for that discussion.

The attempt by the Studienstiftung to justify itself in the face of these criticisms is reminiscent of its handling of the social critique in the 1970s. The Studienstiftung published two evaluation studies in 2010 and 2016, focusing on the social origin of its students. However, these studies did not have the aim of problematising the actions of the Studienstiftung but were intended rather to ensure the quality of the selection and support of gifted students. The ostensible reason for these studies was the massive growth of the Studienstiftung since 2005, and the public perception that the Studienstiftung prefers students who are socioeconomically privileged (see Roth, 2009, p. 4). As in the 1970s, the Studienstiftung did not refer to previously published studies, in this case Middendorff et al. (2009) and Kerbusk (2009). Similarly, the Studienstiftung introduced an additional selection procedure based on the direct application of students without a referral from schools or universities and using a standardised test developed by ITB Consulting (the successor organisation to the ITB). In comparison to the traditional selection procedure, which is still based on recommendations (7719 candidates, 2202 confirmations), the new selection procedure ( 1074 candidates, 87 confirmations) does not have a significant impact on the selection of gifted students (see Studienstiftung, 2018). However, unlike in the 1970s, this new selection procedure has been followed by other measures, such as cooperation with organisations that focus on social equity, an additional recommendation of FGS by principals of schools, the sensibilisation of the selection committee to the issue of social inequality, and visits by Studienstiftung scholars to schools to inform students about the opportunity to apply for a scholarship.

As in the 1970s, the Studienstiftung uses several strategies to show that it offers equal chances for FGS and students from the lower classes. In the first evaluation study in 2010, the Studienstiftung found similar results to those of Middendorff et al. (2009) and Kerbusk (2009). First, it externalised the reason for the underrepresentation of FGS and students with a low social status to other parts of the educational system (see Roth, 2009). Second, the Studienstiftung referred to other studies that show that the socioeconomic backgrounds of students who apply for a scholarship are reflected proportionally among those who are selected (see Roth, 2009). Third, in 2016, the Studienstiftung published another evaluation study and established a new statistical category: Those students in the top 5\% of the Abitur results. While social statistics show that FGS are still underrepresented $(30 \%)$ in comparison to the total student population $(50 \%)$, the Studienstiftung refers to the top $5 \%$ of best-performing students in the total student population (30\%; see Studienstiftung, 2016a, pp. 9-10). The establishment of this new statistical category can be interpreted as a compromise of the demand to diversify the student population and the concurrent demand for excellence in academic research. However, this category has not been used in any social statistic before and its establishment is not explained, justified, or discussed. Thus, it remains unclear why the Studienstiftung focus on those students in the top 5\% of the Abitur results and not on the top $10 \%$ (like it was done in the Oberprimaner-Auswahl) or $15 \%$ or $20 \%$. Furthermore, the Studienstiftung points out that the percentage of FGS increased between 2010 and 2016 from 21\% to 30\%. But social statistics that focus on the social status of the students are not published. From the perspective of the Studienstiftung, these results show that "the current selection procedure is linked to fairness and equitable" (Studienstiftung, 2016b, p. 33). Fourth, after the establishment of a successful narrative, the Studienstiftung avoided the regular publication of social statistics about the social origin of its scholars, which could have been useful for a comparison with the student population.

To sum up, between 1971 and 1974 and since 2010, the Studienstiftung has used social statistics to react to critique and to justify its work. On both occasions, the specific handling of social statistics went along with the establishment of a successful narrative: The Studienstiftung does not discriminate against FGS, working-class students, or students from the lower class. Strategies like the externalisation of the problem to other parts of the educational system, the peculiar 
construction of statistical categories to measure and compare the social background of gifted students to other students, and the avoiding of publishing social statistics after a success story is established are characteristic for the interplay of justification and critique. Thus, it seems like the specific handling of social statistics makes exigencies of equality and justice invisible. It raises doubts as to whether the diversification of gifted students has occurred and the goal to diversify the members of Studienstiftung has been accomplished.

\section{Discussion and Conclusion}

Higher education institutions are globally confronted with the plea for social diversification of their members and the concurrent demand for excellence in academic research (see Bröckling \& Peter, 2014). Lamont (2009, p. 15) points out that "grants and fellowships are becoming increasingly important as academic signals of excellence." The same is true for scholarships in gifted education programs, which offer a tremendous opportunity to expand economic, cultural, and social capital and a competitive advantage in the educational and occupational system. However, long-standing gifted education programs in Germany like the Studienstiftung have managed to avoid diversifying their members regarding class background. Based on a discourse analysis, I have shown that the spirit of the Studienstiftung and its handling of social statistics are two relevant elements regarding the interplay of justification, critique, and organisational change, which raise doubts that the recent efforts to diversify the student population of the Studienstiftung is a success story. Several social statistics points in the same direction: First, a social statistic, which was published by the German Bundestag, shows that the absolute share of selected FGS has increased from 710 to 807 students between 2010 and 2014 and decreased afterwards again to 714 students in 2017, while the amount of all supported students in the Studienstiftung increased from 11336 in 2010 to 12749 in 2017 (see Deutscher Bundestag, 2018, pp. 10-19). Second, some social statistics published by the Studienstiftung (2020, pp. 251,257$)$ point out that the percentage of students that receive full financial aid have fallen from $13.4 \%$ (2014) to $10.3 \%$ (2019), while the percentage of students that receive only the financial aid, which is independent of their parents' income, has risen from $60.9 \%$ (2014) to $71.5 \%$ (2019).

Finally, I would like to discuss some aspects that could be useful to support the diversification of gifted education. Historically, the Studienstiftung has always had windows of opportunity and persons who have thought intensively about the question of social equality in gifted education. The introduction of neediness as a fundamental criterion in the Studienstiftung, as already implemented between 1925 and 1933, could be the first measure. In 2009, the director of the Studienstiftung, Gerhard Teufel, proposed the introduction of social quo- tas in the Studienstiftung (see Kerbusk, 2009). Other gifted education programs, such as the Hans Böckler Foundation, have established special programs for financially needy students in addition to their regular program. However, this measure might conflict with meritocratic criteria like performance and the inclusion of lowincome students leads to an exclusion of other student groups. A second measure could be the expansion of direct applications by students - thus moving away from the traditional recommendation by schools and universities. Many schools remain unmotivated to recommend students, thereby already excluding potential candidates, and the small number of scholars chosen via direct application renders this option less attractive. However, social statistics imply that direct applications can be a way to diversify students in gifted education programs. Another measure could be the continuous and comprehensive analysis of the social background of gifted students. In the past, the Studienstiftung has avoided publishing social statistics, doing so mainly in response to public pressure. A serious examination would provide an opportunity for self-criticism, remove the necessity for successful narratives, and promote a critical discussion of the handling of social statistics, e.g., the use of categories, indicators, and groups of comparison. Subsequently, the Federal Ministry of Education and Research, which is the main donor to the Studienstiftung and other gifted education programs in higher education, could use its influence to establish obligatory guidance on when and how to construct social statistics in gifted education.

\section{Acknowledgments}

I would like to thank the editors and reviewers for their thoughtful reading and their constructive criticism of my first manuscript.

\section{Conflict of Interests}

The author declares no conflict of interests.

\section{References}

Böker, A. (2021). Über die Rechtfertigung von Begabtenförderung. Eine Diskursanalyse am Beispiel der Studienstiftung des deutschen Volkes [On the justification of gifted education. A discourse analysis on the example of the Studienstiftung des deutschen Volkes]. Springer.

Böker, A., \& Horvath, K. (2018). Ausgangspunkte und Perspektiven einer sozialwissenschaftlichen Begabungsforschung [Starting points and perspectives of a sociological gifted education research]. In A. Böker \& K. Horvath (Eds.), Begabung und Gesellschaft. Sozialwissenschaftliche Perspektiven auf Begabung und Begabtenförderung [Giftedness and society. Social perspectives on giftedness and gifted education] (pp. 7-26). Springer. 
Boltanski, L., \& Chiapello, E. (2007). The new spirit of capitalism. Verso.

Boltanski, L., \& Thévenot, L. (2006). On justification: Economies of worth. Princeton University Press.

Bourdieu, P. (1993). Soziologische Fragen [Sociological questions]. Suhrkamp.

Bourdieu, P. (2001). Die konservative Schule [The conservative school]. In Wie die Kultur zum Bauern kommt. Über Bildung, Schule \& Politik [How culture meets peasants. On education, school, and politics] (pp. 25-52). VSA.

Brake, A., \& Büchner, P. (2012). Bildung und soziale Ungleichheit [Education and social inequality]. Kohlhammer.

Bröckling, U., \& Peter, T. (2014). Mobilisieren und Optimieren [Mobilize and optimize]. Zeitschrift für Erziehungswissenschaften, 17, 129-147.

Desrosières, A. (2014). Statistics and social critique. Partepipazione e conflitto: The Open Journal of Sociopolitical Studies, 7(2), 348-359.

Deutscher Bundestag. (2018). Antwort der Bundesregierung auf die Kleine Anfrage der Abgeordneten Dr. Jens Brandenburg (Rhein-Neckar), Katja Suding, Nicola Beer, weiterer Abgeordneter und der Fraktion der FDP [Response of the federal government to the minor inquiry of Dr. Jens Brandenburg (RheinNeckar), Katja Suding, Nicola Beer, other parliamentarians, and the group of the FDP] (19/6324). https:// dip21.bundestag.de/dip21/btd/19/063/1906324.pdf

Engler, S. (2001). "In Einsamkeit und Freiheit"? Zur Konstruktion der wissenschaftlichen Persönlichkeit auf dem Weg zur Professur ["In loneliness and freedom"? The social construction of scientific personality on the path to professorship]. UVK.

Espeland, W. (2015). Narrating numbers. In R. Rottenburg, S. E Merry, S.-J. Park, \& J. Mugler (Eds.), The world of indicators. The making of governmental knowledge through quantification (pp. 56-75). Cambridge University Press.

Foucault, M. (1974). Nietzsche, die Genealogie, die Historie [Nietzsche, genealogy, history]. In M. Foucault (Eds.), Von der Subversion des Wissens [The subversion of knowledge] (pp. 83-109). Fischer.

Keller, R. (2018). The sociology of knowledge approach to discourse: An introduction. In R. Keller, A.-K. Hornidge, \& W. J. Schünemann (Eds.), The sociology of knowledge approach to discourse. Investigating the politics of knowledge and meaning-making (pp. 16-47). Routledge.

Kerbusk, S. (2009, September 24). Wer hat, dem wird gegeben [He that has plenty of goods shall have more]. Die Zeit. https://www.zeit.de/2009/40/ C-Begabtenfoerderung

Kunze, R.-U. (2001). Die Studienstiftung des deutschen Volkes seit 1925. Zur Geschichte der Hochbegabtenförderung in Deutschland [The Studienstiftung des deutschen Volkes since 1925. On the history of gifted education in Germany]. Akademie.
Lamont, M. (2009). How professors think. Inside the curious world of academic judgment. Harvard University Press.

Leemann, R. J., \& Imdorf, C. (2018). Das Potenzial der Soziologie der Konventionen für die Bildungsforschung [The potential of the sociology of the conventions for educational research]. In C. Imdorf, R. J. Leemann, \& P. Gonon (Eds.), Bildung und Konventionen. Die "Economie des conventions" in der Bildungsforschung [Education and conventions. The "Economie des conventions" in educational research] (pp. 3-45). Springer.

Litt, T. (1930). Zur Auslese der Begabten [On the selection of gifted students]. In Studentenwerk (Eds.), Vierteljahrshefte der studentischen Selbsthilfearbeit [Quarterly report of the student union] (pp. 181-185). Quelle \& Meyer.

Margolin, L. (1994). Goodness personified. The emergence of gifted children. de Gruyter.

Middendorff, E., Isserstedt, W., \& Kandulla, M. (2009). Das soziale Profil in der Begabtenförderung [The social profile in gifted education]. HochschulInformations-System.

Paeckelmann, W. (1927). Die Studienstiftung des Deutschen Volkes [The German Academic Scholarship Foundation]. In Studentenwerk (Eds.), Vierteljahrshefte der studentischen Selbsthilfearbeit [Quarterly report of the student union] (pp. 74-82). Quelle \& Meyer.

Rahn, H. (1974). Begabung und Verhalten [Giftedness and behaviour]. In Jahresbericht 1973 [Annual report 1973] (pp. 40-55). Studienstiftung des deutschen Volkes.

Rahn, H., \& Müller-Hansen, B. (1972). Stimulation im Begabungsprozess. Analyse des Aufnahmejahrgangs 1971 der Studienstiftung [The stimulation in the process of giftedness. An analysis of the selected students of the Studienstiftung in 1971]. In Jahresbericht 1971 [Annual report 1971] (pp. 33-103). Studienstiftung des deutschen Volkes.

Roth, G. (2009). Vorwort [Foreword]. In Jahresbericht 2008 [Annual report 2008] (pp. 4-8). Studienstiftung des deutschen Volkes.

Sikorski, H. (1930). Überfüllung der Hochschulen und Begabtenförderung [Massification of universties and gifted education]. In Studentenwerk (Eds.), Vierteljahrshefte der studentischen Selbsthilfearbeit [Quarterly report of the student union] (pp. 185-189). Quelle \& Meyer.

Spiegler, T. (2015). Erfolgreiche Bildungsaufstiege. Ressourcen und Bedingungen [Successful educational upward mobility. Resources and conditions]. Beltz Juventa.

Spranger, E. (1930). Probleme der Begabtenförderung [Problems of gifted education]. In Studentenwerk (Eds.), Vierteljahrshefte der studentischen Selbsthilfearbeit [Quarterly report of the student union] (pp. 165-181). Quelle \& Meyer. 
Staiger, A. (2004). Whiteness as giftedness: Racial formation at an urban high school. Social Problems, 51(2), 61-181.

Studienstiftung. (1971). Stipendiaten zwischen 1948 und 1968 [Gifted students between 1948 and 1968]. Die Studienstiftung (pp. 52-79). Studienstiftung des deutschen Volkes.

Studienstiftung. (1973). Tätigkeitsbericht 1972 [Activity report 1972]. In Jahresbericht 1972 [Annual report 1972] (pp. 7-17). Studienstiftung des deutschen Volkes.

Studienstiftung. (2016a). Bericht zur zweiten Sozialerhebung der Studienstiftung des deutschen Volkes [Report on the second social survey of the Studienstiftung des deutschen Volkes]. Studienstiftung des deutschen Volkes.

Studienstiftung. (2016b). Erste und zweite Sozialerhebung der Studienstiftung [First and second social survey of the Studienstiftung]. In Jahresbericht 2015 [Annual report 2015] (pp. 30-33). Studienstiftung des deutschen Volkes.

Studienstiftung. (2018). Jahresbericht 2017 [Annual report 2017]. Studienstiftung des deutschen Volkes.

Studienstiftung. (2020). Jahresbericht 2019 [Annual report 2019]. Studienstiftung des deutschen Volkes.

Vester, M. (2015). Die Grundmuster der alltäglichen Lebensführung und der Alltagskultur der sozialen Milieus [The basis patterns of everyday life and culture of social milieus]. In R. Freericks \& D. Brinkmann (Eds.), Handbuch Freizeitsoziologie [Handbook of the sociology of leisure] (pp. 143-187). Springer.

von Ferber, C., Gebhardt, F., \& Pöhler, W. (1970). Begabtenförderung oder Elitebildung? Ergebnisse einer soziologischen Erhebung der Forschungsstelle des Sozialwissenschaftlichen Seminars der Technischen Universität Hannover über das Förderungsprogramm der Hochbegabtenförderungswerke [Gifted education or elite education? Findings of a sociological study of the research department of the Sozialwissenschaftliches seminar of the technical university Hannover about the gifted education programs]. Vandenhoeck \& Ruprecht.

Wehler, H.-U. (2008). Vom Beginn des Ersten Weltkriegs bis zur Gründung der beiden deutschen Staaten 1914-1949 [From the beginning of the First World War until the foundation of the two German states 1914-1949]. Beck.

Wirtschaftshilfe. (1926). Studienstiftung des Deutschen Volkes [German Academic Scholarship Foundation]. In Die Wirtschaftshilfe der Deutschen Studentenschaft (Eds.), Geschäftsberichte der Wirtschaftshilfe der Deutschen Studentenschaft e.V. und der Darlehnskasse der Deutschen Studentenschaft [Annual report of the German Student Union] (pp. 29-36). de Gruyter.

Zimmermann, R. (1996). Welche Bildung brauchen Studenten für die Zukunft [Which Bildung do students need for their future]? In Jahresbericht 1995. Fakten und Analysen [Annual report. Facts and analysis] (pp. 11-22). Studienstiftung des deutschen Volkes.

\section{About the Author}

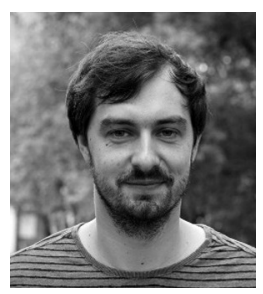

Arne Böker is a post-doctoral researcher at the Institute for Higher Education Research (HoF) at Martin Luther University of Halle-Wittenberg, Germany. He holds a PhD in sociology from Leibniz University Hannover. His research focuses on educational inequalities, educational mobility, and gifted education. 